\title{
Eixos de convergência da alfabetização científica e técnica no Ensino Médio Integrado
}

\section{DOI 10.26512/lc.v24i0.21586}

Sebastião Rodrigues-Moura Instituto Federal de Educação, Ciência e Tecnologia do Pará/Departamento de Ensino, Pesquisa, Extensão e Pós-Graduação, Campus Parauapebas, sebastiao.moura@ifpa.edu.br

Licurgo Peixoto de Brito Universidade Federal do Pará/Instituto de Educação Matemática e Científica e Instituto de Ciências Exatas e Naturais, licurgo.brito@ufpa.br

\section{Resumo}

Com a finalidade de analisar e discutir os indicadores atuais da etapa final da educação básica no Brasil frente às propostas de sua reformulação, elencamos e analisamos eixos de convergência para a promoção da Alfabetização Científica e Técnica ( $A C T$ ) no ensino médio integrado a estudantes que almejam uma formação mais consolidada com o papel cidadão, aborde temas socialmente relevantes, vislumbre decisões a serem tomadas frente a situações-problemas do cotidiano, bem como destaque seu papel de protagonista na sociedade. Para tanto, ocupamo-nos em abordar reflexões iniciais sobre indicadores de desempenho dos estudantes e o atual panorama do ensino médio no Brasil, destacando ao longo do texto a proposição de um curso integrado, defendida por pesquisadores da educação brasileira. Com enfoque metodológico qualitativo, com caráter exploratório do tipo documental, analisamos, à luz da Análise Textual Discursiva (ATD), documentos oficiais de cursos técnicos integrados ao ensino médio de uma instituição federal de ensino no contexto amazônico-paraense na busca de elementos de aproximação em educação, ciência e sociedade com vistas à $A C T$. Dessa análise emergiram quatro eixos de convergência, identificados como a (i) Prioridade a uma formação humanística e reflexiva, (ii) Elementos de interdisciplinaridade e contextualização, (iii) Formação para a cidadania, e (iv) Investigação social para a tomada de decisões conscientes. Desses eixos, observamos, notadamente, que os resultados obtidos apresentam uma aproximação para a discussão, debate e fomento à educação, à ciência e a elementos de questões sociais para a formação regional.

Palavras-chave: Pontos de convergência. Alfabetização Científica e Técnica. Ensino médio integrado. Contexto amazônico-paraense. 


\section{Abstract}

With the purpose of analyzing and discussing the current indicators of the final stage of basic education in Brazil in the face of the proposals for its reformulation, we list and analyze convergence axes for the promotion of Scientific and Technical Literacy (STL) in integrated secondary education for students who aim for more formation consolidated with the citizen's role, approach socially relevant themes, glimpse decisions to be taken in the face of everyday situations and problems, as well as highlight its role as protagonist in society. For this, we focus on initial reflections on student performance indicators and the current panorama of secondary education in Brazil, highlighting throughout the text the proposal of an integrated course, defended by brazilian education researchers. With a qualitative methodological focus, with an exploratory nature, of the document type, we analyzed, in the light of the Discursive Textual Analysis (DTA), official documents of technical courses integrated to the high school of a federal teaching institution in the amazonian-paraense context, in search of elements of approach in education, science and society for Scientific and Technical Literacy (STL). From this analysis emerged four axes of convergences, identified as the (i) Priority to a humanistic and reflexive formation, (ii) Elements of interdisciplinarity and contextualization, (iii) Training for citizenship, and (iv) Social research to make conscious decisions. From these axes, we note, in particular, that the results obtained present an approximation for the discussion, debate and promotion of education, science and elements of social issues for regional formation.

Keywords: Convergence points. Scientific and technical literacy. Integrated secondary education. Amazonian-Paraense context. 


\section{Resumen}

Con el fin de analizar y discutir los indicadores actuales de la etapa final de la educación básica en Brasil frente a las propuestas de su reformulación, elencamos y analizamos ejes de convergencia para la promoción de la Alfabetización Científica y Técnica (ACT) en la enseñanza media integrada a estudiantes que desean una formación más que se consolida con el papel ciudadano, aborde temas socialmente relevantes, vislumbre decisiones a tomar frente a situaciones-problemas de lo cotidiano, así como destaque su papel de protagonista en la sociedad. Para ello, nos ocupamos de abordar reflexiones iniciales sobre indicadores de desempeño de los estudiantes y el actual panorama de la enseñanza media en Brasil, destacando a lo largo del texto la propuesta de un curso integrado, defendida por investigadores de la educación brasileña. Con un enfoque metodológico cualitativo, con carácter exploratorio, del tipo documental e, analizamos a la luz del Análisis Textual Discursivo (ATD), documentos oficiales de cursos técnicos integrados a la enseñanza media de una institución federal de enseñanza en el contexto amazónico-paraense, en la búsqueda de elementos de aproximación en educación, ciencia y sociedad con vistas a la ACT. De ese análisis surgieron cuatro ejes de convergencia, identificados como la (i) Prioridad a una formación humanística y reflexiva, (ii) Elementos de interdisciplinaridad y contextualización, (iii) Formación para la ciudadanía, y (iv) Investigación social para la toma de decisiones conscientes . De esos ejes, observamos, notadamente, que los resultados obtenidos presentan una aproximación para la discusión, debate y fomento a la educación, a la ciencia y a elementos de cuestiones sociales para la formación regional.

Palabras clave: Puntos de convergencia. Alfabetización científica y técnica. Enseñanza media integrada. Contexto amazónico-paraense. 


\section{Résumé}

Afin d'analyser et de discuter des indicateurs actuels de la phase finale de l'éducation de base au Brésil avant des propositions pour une refonte, nous analysons liste et axes de convergence à la promotion de la Culture Scientifique et le Lycée Technique (CSLT) intégré les étudiants qui recherchent plus de formation consolidé le rôle des citoyens, en abordant des thèmes socialement pertinents entrevoient des décisions à prendre avant aux situations problèmes quotidiens et mis en évidence son rôle de premier plan dans la société. Par conséquent, nous nous occupâmes d'aborder des réflexions initiales sur les indicateurs de performance des élèves et la situation actuelle de l'école secondaire au Brésil, en soulignant dans le texte de proposer un cours intégré, tenu par de nombreux chercheurs de l'éducation au Brésil. Avec l'approche méthodologique qualitative, à caractère exploratoire, du type de document, nous analysons la lumière du Discours Analyse Textuelle (DAT), documents officiels de cours techniques intégrés dans l'école secondaire d'un établissement d'enseignement fédéral dans le cadre amazonien-paraense, la recherche d'éléments d'approche dans l'éducation, science et société en vue de CSLT. De cette analyse émergé convergence quatrième axe, identifié comme (i) La priorité à une formation humaniste et de réflexion, (ii) Des éléments interdisciplinaires et contextuels, (iii) La formation à la citoyenneté, et (iv) La recherche sociale pour prendre des décisions éclairées. Ces axes, ont noté, notamment, que les résultats présentent une approche à la discussion, le débat et promouvoir l'éducation, la science et les éléments des problèmes sociaux pour la formation régionale.

Mots-clés: points de convergence. Alphabétisation scientifique et technique. Enseignement secondaire intégré. Contexte Amazonien-Paraense.

\section{Reflexões iniciais}

A formação dos estudantes para a cidadania deve permear toda a sua carreira educacional e compreender sua continuidade até a formação profissional, pois permite ao aluno sentir-se como um membro de uma comunidade, de um grupo social para que seja capaz de tomar decisões pensando-se no coletivo, tomando decisões consciente e respeitando o meio com o qual interage.

Nessa concepção de formação humana, Moura et al. (2015) a considera como resultante das relações entre fatores sociais e de produção na qual a escola é considerada um espaço institucionalizado e fruto dessas relações, aportada nas forças produtivas das ciências, da técnica e da tecnologia que, apesar de dominada pelo sistema capitalista, 
tornou-se "essencial" à sociabilidade humana. Alinhado a essa formação, Cunha (2008) aponta

um ensino médio integrado com indicadores que anunciam uma concepção de formação humana, com base na integração de todas as dimensões da vida no processo educativo, visando à formação omnilateral dos sujeitos. Essas dimensões são o trabalho, a ciência e a cultura. $O$ trabalho compreendido como realização humana inerente ao ser (sentido ontológico) e como prática econômica (sentido histórico associado ao modo de produção); a ciência compreendida como os conhecimentos produzidos pela humanidade que possibilita o contraditório avanço das forças produtivas; e a cultura, que corresponde aos valores éticos e estéticos que orientam as normas de conduta de uma sociedade. (p.109, grifos nossos)

Frente a essas discussões, é tão sabido que essa formação deve refletir uma integraçãoação entre a teoria e prática, repensando-se em toda a estruturação escolar como uma solução transitória. Acerca da reforma do ensino médio no Brasil, desde as informações preliminares divulgadas em mídias diversas até a promulgação da Medida Provisória n. 746, de 22 de setembro de 2016, no Diário Oficial da União - DOU n. 184-A, de 23 de setembro de 2016 , bem como de sua conversão na Lei $n^{\circ} 13.415$, de 16 de fevereiro de 2017 - ficou no centro das atenções dos estudantes, professores e pesquisadores educacionais como um tema emergente para conhecimento social. Trata-se, portanto, de um arcabouço de informações que a sociedade brasileira debate, mas requer um conhecimento mais consolidado sobre os seus fundamentos e teorias que asseguram a base de um ensino médio integrado, com flexibilização dos conteúdos, melhorias na qualidade de ensino, possibilidades educacionais e profissionais diversificadas e qualificadas aos estudantes, entre outras ações de políticas públicas asseguradas.

No atual cenário político e econômico brasileiro, cabe questionar: Quais os pontos cruciais a serem debatidos como instrumentos legais que prevêem e direcionam às mudanças no ensino médio no Brasil? E, nessa linha de discussão, como a alfabetização científica e técnica pode contribuir para áreas de conhecimento de ciências da natureza e suas tecnologias durante o ensino médio? Seguindo esse raciocínio de questionamentos, embasamos essa proposta com abordagem qualitativa, de caráter estudo de caso, como uma investigação voltada para analisar e discutir os indicadores atuais do ensino médio no Brasil com vistas à sua reformulação e à promoção da alfabetização científica e técnica em um curso integrado de uma instituição federal de ensino, localizada na região amazônica brasileira, mais especificamente no estado do sul do estado do Pará.

Pretendemos, dessa forma, trazer discussões e análises voltadas para um ensino médio integrado no âmbito do contexto amazônico-paraense, ocupando-nos em um primeiro momento em trazer as discussões que impulsionam e circunstanciam o panorama atual para a reforma do ensino médio no Brasil e, em seguida, apresentar o desvelamento da proposta da Alfabetização Científica e Técnica (ACT) para o contexto do ensino 
médio como premissa de aproximação para uma aprendizagem científica alinhada a elementos da educação, ciência e sociedade.

\section{O cenário atual do ensino médio brasileiro}

Apesar de supostamente recentes, as ideias para reformular o ensino médio já vem sendo discutidas há muito tempo por pesquisadores e estudiosos da área. Alguns fatores vêm impulsionando esses debates para projetar um ensino médio com resultados mais satisfatórios a nível nacional e internacional.

Um dos fatores que avalia o desenvolvimento dos estudantes do ensino médio é o IDEB (Índice de Desenvolvimento da Educação Básica), instituído em 2007 pelo Instituto Nacional de Estudos e Pesquisas Educacionais Anísio Teixeira (INEP), que é capaz de avaliar a qualidade da aprendizagem nacional dos estudantes e prevê para a melhoria do ensino algumas metas que devem ser atingidas. O IDEB é capaz de balizar e monitorar a qualidade da educação ofertada nas instituições de ensino por meio da taxa de rendimento escolar e o desempenho dos estudantes nos exames aplicados pelo INEP.

Entretanto, desde 2011, o IDEB do ensino médio no Brasil está estagnado, conforme mostra a Tabela 1 e, apesar de novas projeções com metas estabelecidas, há a incerteza de se atingir esse resultado frente aos últimos, para isto tornam-se necessários mais investimentos em infraestrutura e aprimoramento da formação continuada de professores.

Tabela 1: IDEB do Ensino Médio no Brasil

\begin{tabular}{lllllll}
\hline Ano & 2007 & 2009 & 2011 & 2013 & 2015 & 2021 \\
Metas & 3.4 & 3.5 & 3.7 & 3.9 & 4.3 & 5.2 \\
IDEB & 3.5 & 3.6 & 3.7 & 3.7 & 3.7 & - \\
\hline
\end{tabular}

Fonte: Diretoria de Avaliação da Educação Básica - DAEB/INEP

Esse indicador mostra um dos fatores de preocupação das políticas educacionais voltadas para o ensino médio, haja vista que uma reformulação curricular permite levar os estudantes a alcançar 5.2 pontos até 2021 e 6.0 pontos em 2022 - média correspondente ao sistema educacional dos países da Organização para a Cooperação e Desenvolvimento Econômico (OCDE) - sendo este um dos objetivos do governo federal junto ao Ministério da Educação.

Além do IDEB, o desempenho dos estudantes em Língua Portuguesa e Matemática em 2015 foi considerado menor que em 1997, conforme mostra a Tabela 2, concentrando 
outro problema para da educação básica e preocupando o governo para apostar em mudanças.

Tabela 2: Desempenho de estudantes do ensino médio

\begin{tabular}{llllll}
\hline Ano & 1995 & $\ldots$ & 2011 & 2013 & 2015 \\
\hline Língua Portuguesa & 290,0 & $\ldots$ & 268,57 & 264,06 & 267,06 \\
\hline Matemática & 281,9 & $\ldots$ & 274,83 & 270,0 & 267,00 \\
\hline
\end{tabular}

Fonte: Diretoria de Avaliação da Educação Básica - DAEB/INEP

Apesar de os estudantes terem apresentado proficiência em língua portuguesa e matemática de 2015 maior que a de 2011, esse fato não é capaz de esconder o nível já obtido por estudantes em anos anteriores, deixando os estudantes brasileiros na última avaliação no nível $2 / 8$, de acordo com escala do MEC, em língua portuguesa e no nível 2/10 em matemática, o que indica dificuldades em interpretações de texto e operações matemáticas como somar, subtrair, multiplicar e dividir. Além disso, é importante frisar que, no ensino médio, a proficiência considerada adequada deve chegar a pelo menos 300 em língua portuguesa e 350 em matemática, conforme o desempenho dos países desenvolvidos na avaliação internacional feita pelo Programa Internacional de Avaliação de Estudantes (PISA).

Outro dado que preocupa é a visibilidade da educação básica no Brasil a nível internacional. Os dados do PISA demonstraram que os conhecimentos e habilidades dos estudantes brasileiros caíram e o país ficou na $63^{a}$ posição em ciências, na $59^{a} \mathrm{em}$ leitura e na $66^{\text {a }}$ colocação em matemática. Esses resultados deixam evidentes que os estudantes do ensino médio no Brasil estão abaixo do nível de proficiência nas três áreas avaliadas.

O ensino médio integrado pode contribuir para melhorar essa projeção? É uma resposta ainda incerta, mas com possibilidades de trazer subsídios para a educação brasileira. Dados de pesquisa da Confederação Nacional da Indústria (CNI) revelaram que apenas $6 \%$ dos jovens brasileiros, com idades entre 16 e 24 anos, estão matriculados em cursos de educação profissional, quando na OCDE a média registrada é de $35 \%$, considerando estudantes que cursam o ensino médio integrado ao técnico e aqueles que cursam somente o ensino profissional. Ainda registaram que 1,7 milhão de jovens de 15 a 17 anos estão fora das salas de aula, apenas $44 \%$ da população entre 16 e 24 anos estuda, com uma taxa de $18 \%$ que ingressam no ensino superior e $15 \%$ no ensino médio.

Não só os dados anteriormente discutidos, mas também o fato de o ensino médio do Brasil ser o único com um padrão de várias disciplinas que, apesar de incentivarem a interdisciplinaridade, a maioria destas "não dialoga" com as outras na prática docente e em sua metodologia de trabalho. Para isso, o novo ensino médio prima pelo incentivo do tempo integral das turmas nas escolas, a fim de ampliar gradualmente a carga 
horária, das atuais 800 horas para 1400 horas, garantir a flexibilidade do currículo e dar ênfase em cinco áreas de conhecimento: linguagem, matemática, ciências da natureza, ciências humanas e formação técnico-profissional.

Cabe destaque que as amostras do PISA/ 2015 consideraram que 77,7\% estavam no ensino médio e agora consideram as competências dos estudantes para explicar fenômenos cientificamente, avaliar e planejar experimentos científicos e interpretar dados e evidências cientificamente, com perguntas associados aos temas que envolvem os sistemas físicos, vivos e sobre a Terra e o espaço, a nível pessoal, local/nacional e global. O desempenho dos brasileiros em ciências atingiu 401 pontos, quando a média dos países da OCDE chega a 493 pontos.

Portanto, reformular o ensino médio no Brasil é uma discussão-ação emergente, haja vista que há muito tempo o modelo não apresenta os resultados tão esperados nas avaliações nacionais e internacionais, o que deve garantir uma flexibilidade no currículo, articulando-se com a educação profissional, conforme prevêem as competências educacionais do século XXI, a fim de promover um ensino médio integrado e buscando o alinhamento com políticas públicas educacionais internacionais, formação inicial e continuada docente, valorização dos professores e foco na autonomia e protagonismo dos estudantes.

O que a legislação regulamenta para o novo ensino médio? Com a publicação da Medida Provisória n. 746, de 22 de setembro de 2016, no Diário Oficial da União, todos os olhares no Brasil voltaram-se para analisar este documento, principalmente pelo fato de instituir a política de fomento à implementação de escolas de ensino médio em tempo integral, apresentar alterações na lei $n^{\circ}$ 9.394, de 20 de dezembro de 1996, que constitui as diretrizes e bases da educação nacional, na lei $n^{\circ} 11.494$ de 20 de junho 2007, que normatiza o fundo de manutenção e desenvolvimento da educação básica e de valorização dos profissionais da educação e regimenta outras providências legais.

Mas para quê integrar os componentes curriculares do ensino médio? Para a flexibilização do currículo, o governo federal junto ao ministério da educação e colaboradores estão desenhando uma Base Nacional Curricular Comum (BNCC) com cinco possíveis itinerários formativos, definidos por Linguagens; Matemática; Ciências da Natureza; Ciência Humanas e Formação Técnica Profissional, dando autonomia aos sistemas de ensino, cabendo a eles definir e organizar as áreas de conhecimento, as competências e habilidades, bem como as expectativas de aprendizagem definidas na Base.

Dessa forma, haverá a implementação das escolas de ensino médio em tempo integral e integrado com ampliação da carga horária mínima anual, progressivamente, para 1400 horas, caracterizando o ensino de língua portuguesa e matemática como obrigatórios nos três anos do ensino médio e restringindo a obrigatoriedade do ensino da arte e da educação física à educação infantil e ao ensino fundamental, tornando-as facultativas no ensino médio. Além disso, torna obrigatório o ensino da língua inglesa a partir 
do sexto ano do ensino fundamental e nos currículos do ensino médio, facultando neste, o oferecimento de outros idiomas, preferencialmente o espanhol, de modo a permitir inclusive que conteúdos cursados no ensino médio possam ser aproveitados no percurso do ensino superior.

Esta forma de como o currículo será reformulado já é apresentada em países desenvolvidos como Inglaterra, Canadá, Estados Unidos da América, Canadá e Portugal, por exemplo, o que irá possibilitar organização em módulos com sistemas de crédito, bem como o reconhecimento de conhecimentos, saberes, habilidades e competências do estudantes em atividades com demonstração prática, experiência de trabalhos diversos, atividades de educação técnica, bem como cursos em centros ocupacionais e na forma de oferta a distância. Garante assim, a possibilidade de inovação curricular do ensino médio conforme as características da aprendizagem dos estudantes, as especificidades das escolas e das regiões brasileiras, uma vez que os currículos de formação de professores terão como referência a BNCC e suas definições, como documento fundamental norteador do ensino médio.

Quanto à educação profissional integrada ao ensino médio, esta apresentará uma parte flexibilizada da formação técnica, o que deve garantir a inclusão da experiência prática de trabalho no setor produtivo, a concessão de certificações intermediárias, com oferta experimental além das que estão previstas nos Catálogos Nacionais de Cursos Técnicos, absorvendo, por sua vez, professores com notório saber na área, como já acontece em cursos técnicos profissionalizantes no Brasil, em que os instrutores possuem experiência na área, mesmo sem a formação específica para este fim..

\section{A alfabetização científica e técnica para o contexto do ensino médio integrado}

Frente ao panorama do ensino médio atual e as propostas de reformulação, já vem se notando uma acentuada produção científica de pesquisadores da educação em ciências no Brasil que destacam a inserção dos conteúdos tradicionais que os currículos apresentam durante o ensino médio e apostam em posturas didáticas para a mudança no currículo escolar (Frigotto et al., 2005; Moura et al., 2015; RodriguesMoura, 2016). E, havendo a inclusão de temas atuais da ciência capazes de motivar tanto os estudantes como os professores a um novo panorama educacional, o ensino médio integrado deve apresentar uma nova realidade a ser vivenciada pelos alunos das escolas brasileiras.

O estudante atual está muito atento às inovações tecnológicas e às informações científicas que são veiculadas nas diversas mídias. Por que então não ensinar conteúdos de ciências tão instigantes, motivadores e vinculados ao cotidiano dos mesmos? Essa 
postura muda radicalmente o pensar sobre a ciência básica ensinada nas escolas e possibilita ao estudante relacionar os fenômenos aos processos científicos e suas implicações humanas e sociais.

Muitas são as discussões e propostas didáticas que apontam para a melhoria na qualidade da aprendizagem de conhecimentos científicos para acompanhar as constantes transformações sociais, modernização de tecnologias e em seus efeitos culturais. Perspectivas e avanços na forma de ensinar ciências tornam-se significativos à medida que novas propostas são implementadas em sala de aula, pois os professores repensam conteúdos de ciências, sua forma de inserção e criam estratégias didáticopedagógicas capazes de estimular os estudantes a buscar entender o mundo no qual estão inseridos.

Sabe-se que o fluxo de informações via televisão, rádio e redes sociais na internet, o uso de computadores ou aparelhos celulares modernos, nos faz repensar no currículo escolar de ciências do ensino médio, tanto na perspectiva de ações pedagógicas compatíveis com a nova realidade tecnológica a que os estudantes têm acesso, como pela abordagem de conteúdos científicos que permitem o funcionamento de equipamentos tecnológicos disponíveis à sociedade, impulsionadas pelos avanços da ciência e tecnologia.

Nessa perspectiva de um ensino de ciências com conteúdos mais atualizados é que apostamos na Alfabetização Científica e Técnica durante o ensino médio integrado, por esperar que as disciplinas científicas tragam à tona assuntos relevantes que omitiram e continuam omitindo o desenvolvimento científico produzido pela humanidade nos últimos séculos, fazendo com que o currículo escolar ainda mantenha-se da forma tradicionalista.

A legislação educacional busca a promoção de novos conteúdos a serem trabalhados em sala de aula com a finalidade de o estudante compreender o mundo atual criado e modificado pelas descobertas humanas. A Lei de Diretrizes e Bases da Educação Nacional (LDB) também menciona uma possível atualização nos currículos, objetivando que o estudante do ensino médio adquira uma maior compreensão do significado da ciência, o domínio dos princípios científicos e tecnológicos que presidem a produção moderna.

O preceito dessa lei já vem sendo observado e detalhado em diversos documentos oficiais, inclusive na Resolução ${ }^{\circ}$ 02/2012 do CNE/CEB, que define as Diretrizes Curriculares Nacionais para o Ensino Médio (DCNEM), particularmente nos artigos $3^{\circ}$ e $4^{\circ}$ em que enfatizam que as unidades escolares devem estruturar seus projetos político-pedagógicos considerando as finalidades previstas na LDB:

III - o aprimoramento do educando como pessoa humana, incluindo a formação ética e o desenvolvimento da autonomia intelectual e do pensamento crítico; 
IV - a compreensão dos fundamentos científico-tecnológicos dos processos produtivos, relacionando a teoria com a prática. (grifos nossos)

Para além do que foi destacado, as DCNEM já apontam para a possibilidade de novas formas de oferta e de organização do ensino médio que estabelecem abertura em documentos oficiais para o trabalho pedagógico centrado no desenvolvimento de valores e atitudes em composição com conteúdos adequados para o atendimento de um antigo anseio de educadores referente ao desenvolvimento de um currículo que permita o desenvolvimento integral de crianças, jovens e adultos, estudantes em nosso país.

De modo geral, a inserção de temas atuais no ensino para a Alfabetização Científica e Técnica (ACT) tem uma abrangência notável que envolve investigações desde os fenômenos da natureza presentes no cotidiano até o desenvolvimento e o funcionamento de máquinas e aparelhos tecnológicos.

Diante desse fato, propomos um alinhamento do ensino de ciências naturais para o ensino médio integrado com o enfoque da ACT que vislumbra elementos coerentes ao âmbito educacional, posto que esse movimento defende a formação de cidadãos conscientes perante os impactos da ciência e dos meios tecnológicos.

Para o papel do ensino de ciências com vistas à promoção da alfabetização científica e técnica, há muito se buscam meios de tornar o estudante o sujeito a protagonizar o seu meio social, diferentemente do ensino tradicional que mantem o indivíduo preso a conteúdos com poucas aplicações em sua realidade. Desse modo, Fourez (1994) estabelece algumas competências de um ensino capaz de desenvolver a ACT no estudante, quando:

(i) utilizar conceitos científicos e integrar valores e saberes para adotar decisões responsáveis à sua vida e compreender que a sociedade exerce um controle sobre as ciências e as tecnologias imprimem seu selo à sociedade;

(ii) reconhecer tanto os limites como a utilidade das ciências e as tecnologias no processo de bem-estar humano, assim como conhecer os principais conceitos, hipóteses, teorias científicas e ser capaz de aplicá-los;

(iii) apreciar as ciências e as tecnologias pela estimulação intelectual que suscitam, bem como entender que a produção de saberes científicos depende enquanto de processos de investigação e de conceitos teóricos;

(iv) saber reconhecer a diferença entre resultados científicos e opiniões pessoais;

(v) reconhecer a origem da ciência e compreender que o saber científico é provisório e sujeito a troca segundo o grau de acumulação de resultados;

(vi) compreender as aplicações das tecnologias e as decisões que sua 
utilização implica possuir suficiente saber e experiência para apreciar o valor da investigação e do desenvolvimento tecnológico;

(vii) extrair de sua formação científica uma visão de mundo mais rica e interessante e conhecer as fontes válidas de informação científica e tecnológica e recorrer a elas quando há de tomar decisões e ter uma certa compreensão da maneira em que as ciências e as tecnologias foram produzidas na história.

Dessa forma, há a necessidade de os estudantes refletirem sobre questões, pressupostos, valores, objetivos, metas e limitações da ciência para com a sociedade, haja vista que a ACT valoriza o conhecimento razoável de determinados temas e sua importância científica, gerando consciência própria nos estudantes e para entender a cultura e a sociedade, com objetivos humanistas, ligados ao social, ao econômico e ao político e visa à formação do cidadão (Fourez, 1994). Chassot (2003) assegura que a ACT é uma dimensão para potencializar alternativas que privilegiam uma educação mais comprometida, envolvendo um conjunto de conhecimentos que visam a capacitar o indivíduo para fazer uma leitura de mundo, possibilitando o entendimento e a tomada de consciência de se fazer parte de um meio no qual está inserido.

Ao promover essa integração curricular, os estudantes lidam com conteúdos atualizados e associados às rápidas mudanças provocadas por meio da evolução da ciência e tecnologia que demandam profundas inovações na formação científica a estudantes imersos em um ambiente globalizado.

A ACT se adequa aos pressupostos educacionais e aponta para as mudanças que culminaram em ideias voltadas para a formação de estudantes imersos em uma comunidade globalizada e sob forte influência das mais modernas tecnologias vigentes. Nesse processo, a educação em ciências busca metodologias eficazes com a finalidade de estimular a aprendizagem de conteúdos científicos e axiológicos, evitando a rotina que permeia as salas de aulas, motivando a participação ativa de estudantes na compreensão de fenômenos científicos e de valores humanos.

Com vistas a um ensino médio integrado, o ensino de ciências com enfoque na ACT deve

proporcionar a todos um caminho potencial para as carreiras científicas e de tecnologia, proporcionar informações sobre a visão científica do mundo, que é de utilidade comprovada para muitos cidadãos, comunicar alguns aspectos do papel da ciência e da tecnologia na vida social, ajudar a desenvolver habilidades de raciocínio lógico complexo e o uso de múltiplas representações. (Lemke, 2006, p. 6, grifos nossos)

É nesse sentido que a ACT incorpora-se ao objetivo geral da nossa proposta argumentativa e sobre o processo de desenvolvimento de um ensino médio integrado no Brasil, capaz de desenvolver a alfabetização científica e técnica, bem como o exercício para a cidadania a estudantes a partir da produção de conhecimentos sobre 
questões diversificadas de ordem ética, político-econômica e sociocultural.

\section{Metodologia da investigação-ação}

$\mathrm{Na}$ presente pesquisa, apresentamos os resultados de uma análise dos fundamentos de uma abordagem pedagógica aplicada à Educação Profissional Técnica de Nível Médio do Instituto Federal de Educação, Ciência e Tecnologia do Pará (IFPA), Campus Parauapebas, assim denominado por estar localizado no município com o mesmo nome, sudeste do estado do Pará, Amazônia, Brasil, sobre a qual traremos reflexões e as confluências entre ciência, educação e sociedade existentes na proposta. Para chegarmos a essa discussão, buscamos estruturar a pesquisa em uma abordagem qualitativa, com caráter exploratório, para que coletássemos dados e pudéssemos analisá-los.

Do exposto, a literatura sobre a pesquisa qualitativa conta com seu diferencial ao ocupar análise em intervenções ou ações exploratórias, por analisar fenômenos relacionados pessoas ou grupos de pessoas, documentos ou acervos, dada sua amplitude de facilitar a compreensão nas mais variadas dimensões de espaço e tempo. Os trabalhos de Godoy (1995) servirão como nossa base de dados metodológica pelo fato de direcionar a pesquisa qualitativa como

um fenômeno pode ser melhor compreendido no contexto em que ocorre e do qual é parte, devendo ser analisado numa perspectiva integrada. Para tanto, o pesquisador vai a campo buscando "captar" o fenômeno em estudo a partir da perspectiva das pessoas nele envolvidas, considerando todos os pontos de vista relevantes. Vários tipos de dados são coletados e analisados para que se entenda a dinâmica do fenômeno. (p. 21, grifos nossos)

Para além do que foi destacado, observamos que a pesquisa qualitativa requer do pesquisador um olhar diferenciado sobre a parte e sobre o todo no qual está inserido o objeto de estudo/pesquisa, caracterizando-se como um molde que deve ser utilizado para que consiga obter as informações consideradas relevantes, em uma visão integradora e que lhe permita discorrer sobre o fenômeno da melhor forma possível.

Portanto, não é tarefa fácil pensar em pesquisa qualitativa como sendo de fácil compreensão e uso pelo pesquisador que faz uma análise, pois requer dele uma visão local e sua ampliação para buscar caracterizar o fenômeno e elencar meios de compreender a dinamização do fenômeno para com o ambiente no qual se insere e suas variadas possibilidades de interpretar os dados coletados.

Da pesquisa qualitativa, há três vertentes e possibilidade de realizá-la - a pesquisa documental, o estudo de caso e a etnografia - cada uma com suas características, particularidades e suas especificidades, porém iremos nos ater à pesquisa documental 
por nos amparar mais ao nosso estilo de investigação para este artigo e ao processo que iremos conduzir na intervenção pedagógica dos documentos oficiais da instituição. A pesquisa documental nos proporciona a vantagem de alinhar o objeto de estudo acerca das confluências entre as vertentes da ciência, educação e sociedade, para que possamos analisá-los com maior profundidade.

Godoy (1995) referencia que a pesquisa documental tem uma abordagem qualitativa

enquanto exercício de pesquisa, não se apresenta como uma proposta rigidamente estruturada, ela permite que a imaginação e a criatividade levem os investigadores a propor trabalhos que explorem novos enfoques. Nesse sentido, acreditamos que a pesquisa documental representa uma forma que pode se revestir de um caráter inovador, trazendo contribuições importantes no estudo de alguns temas. (p. 21, grifos nossos)

Do exposto, observa-se que a pesquisa documental pode ir além das fronteiras da investigação ao se fazer pesquisa empírica e analisar situações encontradas no seu próprio contexto da realidade, onde o fenômeno apresenta uma fronteira não tão bem estabelecida com esse ambiente. Cabe assim ao pesquisador utilizar os vários olhares de sua experiência para interpor o que fora observado, escolher os documentos pertinentes à sua pesquisa, pensar como intervir sobre a sua análise, tendo em vista as suas multifaces. Para esta ação, nos apropriamos de dois Projetos Pedagógicos de Cursos (PPC) de cursos técnicos integrados ao ensino médio e optamos em análisálos frente às técnicas da Análise Textual Discursiva (ATD), proposta por Moraes e Galiazzi (2011).

Após a escolha dos documentos, preocupamo-nos em codificar e analisar os dados. Dessa forma, por termos acesso aos documentos oficiais, considerados de domínio público, apoiamo-nos em fazer uma leitura e buscar elementos e fragmentos dos nossos objetos de investigação. Estes, portanto, são os materiais empíricos da presente pesquisa.

Para esta pesquisa documental, iremos aprofundar nossos olhares para a implantação de ensino médio integrado no Instituto Federal de Educação, Ciência e Tecnologia do Pará, campus Parauapebas, com a finalidade de obter uma forma de melhor referenciar os resultados e, para essa situação, trazer argumentos e um diálogo com outros materiais da literatura. A ATD servirá para compormos nossos dados analisados por meio de eixos analíticos, os quais emergiram dos passos tomados, nesta ordem:

I. Foram feitas leituras em documentos oficiais que regem a implantação do ensino médio integrado para que pudéssemos encontrar elementos comuns ao longo dos textos expressos, com o objetivo de afinar e agrupar conforme o que fora escrito;

II. As leituras nos documentos foram exaustivas para que pudéssemos obter 
dados consistentes e, dessa forma, encontrar unidades entre os mais variados elementos encontrados;

III. Após essa ação, os elementos que apresentavam similaridades ou características comuns foram organizados em unidades de análise;

IV. Das unidades de análise, recriamos categorias de discussão para que pudéssemos estar alinhados ao objeto de pesquisa e ter uma discussão mais ampla;

V. Diante da categorização, desenvolvemos quatro eixos analíticos para que fossem agrupados da forma mais apropriada a discussão textual e argumentação, conforme propõem Moraes e Galiazzi (2011).

Para tanto, consideramos essas etapas como essenciais para que, por meio da ATD, voltássemos nossos olhares, percepções e argumentações para o estudo de caso acerca dos fundamentos de uma abordagem teórico-metodológica com vistas às confluências entre ciência, educação e sociedade. Para melhor contextualizar os indicativos dos documentos oficias da instituição de ensino, traremos em nossas discussões fragmentos ou excertos dos materiais empíricos analisados por considerarmos importante trazer parte da proposta do currículo desenhado à instituição, ocupando desta forma nossos argumentos à análise sobre os documentos e textos lidos, mantendo a postura da ATD frente aos argumentos apresentados que emergiram ao longo do percurso citado anteriormente.

Como amostragem dos dados obtidos, foram analisados dois documentos pedagógicos oficiais de cursos técnicos integrados ao ensino médio ofertados inicialmente na instituição, tendo em sua previsão a expansão para cursos de outros eixos de formação técnica, para os quais nos referenciaremos como PPC-MEC para o Projeto Pedagógico do Curso de Mecânica e PPC-ELETRO para o Projeto Pedagógico de Curso de Eletroeletrônica, ambos cursos técnicos integrados ao ensino médio, com duração de três anos, sendo o primeiro com carga horária total de 4080 horas e o segundo com 3810 horas, relacionadas aos itinerários formativos de um núcleo estruturante, um núcleo articulador, um núcleo tecnológico, do estágio curricular supervisionado, de uma base diversificada, de componentes optativos e de projetos integradores, bem como de atividades complementares necessárias à formação do egresso.

\section{Pontos de convergências para fomentar a alfabetização científica e técnica}

A partir do exposto e das discussões apresentadas, ocupamo-nos de elencar alguns pontos de convergência que consideramos relevantes para se trabalhar no 
percurso do ensino médio integrado junto aos componentes curriculares voltados para as ciências da natureza e suas tecnologias no percurso de um ensino médio integrado, priorizando-se a formação de estudantes socialmente protagonistas de sua realidade, conforme destaca as competências de um ensino proposto por Fourez (1994), a citar:

\section{(1) Prioridade a uma formação humanística e reflexiva}

Observamos que a formação do egresso e a proposta de implantação de cursos de ensino médio integrado na instituição pesquisada não foram consideradas apenas como uma forma maciça de se transmitir os conhecimentos dos professores para os estudantes, sem considerá-los como sujeitos socialmente ativos e protagonistas de seu papel na realidade, apesar de os cursos terem o eixo de formação técnica. $\mathrm{Na}$ atual realidade acadêmica, nota-se que a proposta busca conduzir os estudantes a refletir a sua formação humana, de modo a levá-los a elucubrar sobre sua prática cotidiana de vida.

Diante desse perfil formativo, observa que em um dos documentos oficiais é apresentado que haverá um estímulo à

participação e organização de eventos e atividades relacionadas à temáticas previstas na legislação, tais como o processo de envelhecimento, o respeito e valorização do idoso, de forma a eliminar o preconceito e a produzir conhecimentos sobre a matéria (Lei no 10.741/2003, que dispõe sobre o Estatuto do Idoso); Educação para o Trânsito (Lei $n^{\circ}$ 9.503/97, que institui o Código de Transito Brasileiro); Educação em Direitos Humanos (Decreto $n^{\circ} 7.037 / 2009$, que institui o Programa Nacional de Direitos Humanos - PNDH) e o Estatuto da criança e adolescente. (PPC-ELETRO, 2016, p. 26 , grifos nossos)

Do exposto, observa-se que há uma necessidade de conduzir os estudantes a serem autores de sua própria realidade e praticarem atividades que relacionam direitos sociais e formação sócio-humanística, desenvolvendo uma formação reflexiva diferenciada para que possam protagonizar ações coletivas pensando-se no bemestar social e não em um ser individualizado, haja vista que o contexto contemporâneo conduz a pensarmos não como sujeito único, mas sempre na coletividade.

Nessa ação, os projetos integradores surgem como um meio de possibilitar aos estudantes a interação dos conhecimentos adquiridos ao longo do processo formativo e, dessa forma, ao final do curso é possível que o egresso atinja o seu perfil formativo, pois durante o curso almeja-se

a formação de um profissional com capacidade de pensar de forma reflexiva, com autonomia intelectual e sensibilidade ao relacionamento interdisciplinar, capaz de aplicar, em uma mesma atividade um universo de informações adquiridas através 
dos vários contextos e situações de aprendizagem vivenciadas. (PPC-MEC, 2014, p. 54 , grifos nossos)

Observa-se que o planejamento de um ensino médio integrado para oferecer sólida formação humanística e reflexiva diante de temas variados no itinerário formativos prioriza não só a formação em componentes curriculares específicos, mas busca aproximar os estudantes e tangenciar da sua realidade vivenciada. É, portanto, uma ação didática para formar estudantes que contribuam ao seu papel de cidadão, compreendam e interpretem os fenômenos naturais em decorrência do ser social, sendo capazes de responder pelas suas ações e enfrentar a realidade vivenciada por meio dos conhecimentos científicos construídos.

Frente à sua formação social, humanística e reflexiva, há objetivos dos cursos que permeiam

Possibilitar reflexões acerca dos fundamentos científico-tecnológicos da formação técnica, relacionando teoria e prática nas diversas áreas do saber; (PPC-MEC, 2014, p. 13 , grifos nossos)

Intensificar a interação social dos alunos/as na sala de aula, na escola e em seus contextos sociais e culturais de modo a potencializar a construção de saberes; (PPCELETRO, 2016, p. 12, grifos nossos)

Demonstrar atitude ética e desenvolver autonomia intelectual e o pensamento crítico e saber conviver e trabalhar em equipe; (PPC-MEC, 2014, p. 14, grifos nossos)

Demonstrar atitude ética e desenvolver autonomia intelectual e o pensamento crítico e saber conviver e trabalhar em equipe, com responsabilidade, sociabilidade, integridade, criatividade, ética e honestidade. (PPC-ELETRO, 2016, p. 12, grifos nossos)

Ao longo da leitura, observa que a proposta da instituição para o curso é permeada de uma prática pedagógica que visita a ação-reflexão-ação no qual os estudantes possam criar um compromisso social frente às atitudes humanas com temas relacionados à ciência e tecnologia, impactos ambientais, debates políticos e econômicos e, sobretudo, aqueles que primam pelo desenvolvimento de habilidades pessoais e competências de um cidadão alfabetizado cientificamente.

\section{(2) Elementos de interdisciplinaridade e contextualização}

Outra preocupação da instituição está relacionada com o resultado da qualidade da aprendizagem dos estudantes para que sejam socialmente comprometidos como 
reflexo da postura da didática docente, em especial, quando se é capaz de trabalhar com temas e assuntos em uma linha que conecte as várias áreas de conhecimento e não somente aquela ministrada pelo professor. É preciso que o professor repense o que de fato é considerado relevante para a aprendizagem dos estudantes e não somente aquilo que o sistema burocratiza para ser ensinado.

Mesmo sendo ensino médio, observa-se uma preocupação em alinhar a tríade ensino, pesquisa e extensão ao currículo e à forma de avaliar a aprendizagem do estudante formativo. É nesse sentido que elementos da interdisciplinaridade e contextualização emergem para tornar o processo mais produtivo e integrem essas dimensões, haja vista que deve-se manifestar uma

adesão ao diálogo interdisciplinar, por meio de uma organização curricular que acolha os eixos básico, científico, técnico e tecnológico; Promoção de intercâmbios constantes entre as áreas de conhecimento e as temáticas do cotidiano, conectando aspectos da formação humana, social e profissional; Planejamento conjunto, envolvendo disciplinas, programas e projetos para compor as diretrizes do curso; Condução dialógica, atrelada ao planejamento conjunto, do processo pedagógico de aprendizagem e de desenvolvimento dos estudante; e, Formação continuada para atender às especificidades pedagógicas, no sentido de materializar a aproximação das áreas e as dimensões acadêmicas, verificando as necessidades presentes na realidade da qual os sujeitos fazem parte. (PPC-ELETRO, 2016, p. 43, grifos nossos)

Nesse âmbito, não pode ser considerado como elemento de pretexto do professor que não ministra assuntos e conteúdos que estão mais próximos dos estudantes porque muitos componentes curriculares apresentam um tradicionalismo e uma sequência de tópicos a serem trabalhados em sala de aula. Para que os estudantes estejam cientes dos acontecimentos atualizados e, de sobremaneira, serem sujeitos alfabetizados cientificamente, tem-se que lançar mão a temas interdisciplinares e contextualizados com a realidade vivenciada por eles.

Essa política curricular se reafirma na prática profissional do estudante ao se estabecer que ao adotar essas práticas "possibilita efetivar uma ação interdisciplinar e o planejamento integrado entre os elementos do currículo" (PPC-MEC, 2016, p. 54, grifos nossos), bem como consolida-se na avaliação da aprendizagem dos componentes curriculares que deve ser tratada "de forma interdisciplinar e contextualizada, baseado em critérios que estabelecerão a quantificação do rendimento da aprendizagem do aluno durante todo o percurso acadêmico, coerente com o planejamento pedagógico docente" (PPC-ELETRO, 2016, p. 28, grifos nossos).

A interdisciplinaridade e a contextualização caminham juntas nesse rol da educação básica integrada para o estudo em ciência e tecnologia como uma estratégia de conduzir os estudantes em sua coletividade para destacar conteúdos socialmente significativos para o contexto de um ensino médio integrado, discutir a versatilidade 
da cultura, a relação de distintas classes sociais, os direitos humanísticos, refletir sobre a educação ambiental e fazer com que os estudantes avancem no pensamento de sua inserção social em realidades diferentes e na formação cidadã.

\section{(3) Formação para a cidadania}

Notadamente, os documentos apresentam uma discussão acerca da formação de estudantes para a cidadania como elementos estruturantes para transformar a realidade social com vistas à valorização dos segmentos sociais, da diversidade cultural e regional, bem como avançar socialmente em um mundo globalizado em que a ciência e a tecnologia imprimem um papel crucial para todas as pessoas, sejam para aquelas que as dominam ou não. Refletir sobre as próprias atitudes cria no indivíduo ainda no percurso da educação básica, principalmente em um curso integrado, uma formação crítica, reflexiva e investigativa da própria realidade.

Frente ao entendimento da política de afirmação do ensino, da pesquisa e da extensão no ensino médio integrado, observa-se que estas práticas devem

colaborar com o desenvolvimento local e regional e ofertar educação profissional e tecnológica nos seus diferentes níveis e modalidades, objetivando a formação de cidadãos qualificados e comprometidos com a inclusão social e o desenvolvimento socioambiental, como explicita a visão do campus. (PPC-ELETRO, 2016, p. 43, grifos nossos).

Do exposto, observamos que há a real necessidade da formação cidadã que (re)veja o papel da ciência e da tecnologia não como um fim, mas um meio de contribuição para o bem-estar global, de garantias de acesso ao conhecimento produzido ao longo da história e acumulado para que tenham a capacidade de transformar os diferentes contextos sociais, primando pelo pensamento coletivo e estabeleçam relações de produtividade humanística. É nessa ação que entendemos, tal como o documento apresenta, a possibilidade de formação de profissionais e cidadãos,

tendo o trabalho como princípio educativo, assim como cultura, ciência e tecnologia, pretende-se propiciar, no entrecruzamento dos eixos sociedade, cultura, trabalho, educação e cidadania, a formação humana e formação profissional, com vistas à aquisição de conhecimentos científicos, técnicos, tecnológicos e ético-políticos, propícios ao desenvolvimento integral do sujeito. (PPC-ELETRO, 2016, p. 10, grifos nossos)

Uma das características da missão e visão da instituição é "garantir a integração e diversidade dos saberes e a inclusão dos cidadãos no mundo do trabalho" (PPCMEC, 2014, p. 6, grifos nossos), assim como garantir durante o estágio curricular supervisionado que o estudante possa desenvolver-se "para a vida cidadã e para o mundo do trabalho" (PPC-ELETRO, 2016, p. 24, grifos nossos). 
Para essa ação, ainda é necessária a desmitificação de que o papel da ciência e a tecnologia no percurso da educação profissional pode ser considerado como um processo de educação social que pode assolar a humanidade, mas que em outra vertente de cunho mais social é capaz de propiciar um sólido conhecimento ao cidadão em formação, a estudantes ainda em sua escolarização básica por ser crucial para que este torne-se um sujeito com pensamentos mais abertos, com maturidade e segurança frente aos problemas enfrentados pela sociedade.

\section{(4) Investigação social para tomar decisões conscientes}

Observamos que o currículo do ensino médio integrado possui em sua estrutura uma integração de saberes, bem organizados e planejados, de modo a permitir que os estudantes sejam os protagonistas da sociedade, com a capacidade de investigar e posicionar-se acerca de temas muitas vezes ausentes do contexto educacional. Essa permissão de os estudantes investigarem o seu meio social frente à determinadas situações-problemas está aliada ao papel de decidir e tomar atitudes conscientes com a possibilidade de se aplicar a teoria apreendida em sala de aula com práticas mediadas pelos professores e, posteriormente, ser capaz de coordenar suas ações sociais e exercitar suas habilidades pessoais.

Nesse sentido, nota-se uma postura institucional voltada para o desenvolvimento de estudantes capazes de investigar o meio social e tomem decisões coerentes com o meio no qual vivem, pois dentre os critérios e procedimentos de avaliação do processo de ensino-aprendizagem, tem-se que levar em conta o parâmetro qualitativo da "Autonomia - capacidade de tomar decisões e propor alternativas para solução de problemas, iniciativa e compreensão do seu desenvolvimento" (PPC-MEC, 2014, p. 60; PPC-ELETRO, 2016, p. 30, grifos nossos), tal como relacionado ao seu perfil formativo por trazer na bagagem o exercício da laboralidade de forma autônoma, crítica, reflexiva e consciente, uma vez que os conteúdos que integram o currículo devem estimular a autonomia da aprendizagem do estudante.

É nesse sentido que entendemos que assegurar a autonomia na aprendizagem aos estudantes configura-se como uma peça chave para abrir as possibilidades de os mesmos transporem os conhecimentos construídos no espaço escolar como princípios práticos de sua identidade social, exercitando suas habilidades e buscando as mais coerentes atitudes e escolhendo procedimentos que sua educação lhe permita para agir sobre o seu pensamento humanístico. Como orientação metodológica, são desenhadas ações que devem deixar os estudantes a pensarem sobre suas próprias ações, manifestando seus pensamentos, bem como serem capazes de defender pontos de vistas socialmente relevantes, como meio de "procederem com investigações, observações, confrontos e outros procedimentos decorrentes das situações- 
problema propostas" (PPC-MEC, 2014, p. 58, grifos nossos), que devem ser priorizadas por meio de aulas expositivas dialogadas, práticas laboratoriais, seminários, pesquisas, elaboração e execução de projetos, entre outros.

A investigação social propicia ao estudante as responsabilidades pessoais frente à coletividade social, tomadas de decisões e mudanças no comportamento tradicionalizado e, nesse viés, emergem os projetos integradores dos cursos de esnino médio da instituição, como meio de "fomentar a consciência crítica do sujeitotrabalhador a partir da compreensão da sociedade e suas tecnologias relacionadas ao mundo do trabalho" (PPC-MEC, 2014, p. 21, grifos nossos). Portanto, os documentos oficiais da instituição primam para o desenvolvimento da autonomia discente por meio de várias atividades, o que leva a enxergar que há a possibilidade de durante a educação básica termos cidadãos alfabetizados científica e tecnicamente, reconhecendo seus limites, suas potencialidades intelectuais e, portanto, potencializando suas responsabilidades sociais.

\section{Tecendo algumas considerações}

Em decorrência dos elementos discutidos e diante das análises dos dados, agora dedicamo-nos a tratar de algumas considerações e perspectivas tidas como relevantes acerca da investigação desenvolvida, considerando-se a realidade do currículo escolar de um ensino médio integrado que vem ganhando importantes contribuições pedagógicas e permitem uma reflexão na promoção de uma educação científica e técnica de qualidade, no contexto amazônico-paraense.

Diante da exposição argumentada e dos fragmentos de documentos oficiais da instituição, assumimos que há da ACT por detectar que os projetos pedagógicos são voltados para a formação de estudantes na direção da maior autonomia social a partir da aplicação de práticas pedagógicas diversificadas capazes de integrar os conhecimentos produzidos pelo homem em uma realidade existente, podendo modificá-la para o bem-estar social, para nela atuar e transformar seu meio, pensandose sempre no coletivo. Essa visão totalitária pontua-se e está expressa na prática docente, no ato de ensinar e aprender, de mediar e apreender o conhecimento científico e técnico para fins de compreensão da relação existente entre a educação, a ciência e a sociedade, principalmente diante do contexto amazônico, muitas vezes negligenciado.

Identificamos em nossas análises uma aproximação dos elementos da ACT à relação existente entre ciência, sociedade e educação, os quais apontam para o sentido da formação para a cidadania, de desenvolvimento da autonomia, de posturas de investigação social, de estudantes conscientes de seu papel frente a um currículo 
integrado no ensino médio com vistas à compreensão de sua realidade de vida, os meios econômicos e políticos, sociocultural e, inclusive, do mundo do trabalho moderno, remetendo-nos a uma mudança possível nos dados apresentados nas tabelas 1 e 2 , nas quais os estudantes brasileiros do ensino médio apresentam uma formação ainda não desejada pelos órgãos governamentais e pela própria sociedade.

Do exposto, uma educação integrada com fins de não dissociar o estudante da sociedade pode ser entendido como uma oportunidade essencial para que possamos aceitar com menos rispidez um ensino médio integrado a um curso técnico que permita aos cidadãos refletir sobre a própria prática, superar rupturas sociais com menor impacto na divisão social e da técnica do trabalho e possa superar as barreiras impostas pelos mais variados contextos regionais brasileiros.

No que diz respeito ao ensino médio integrado investigado e frente à ACT, observamos que toda ação didática perpassa pela formação dos estudantes na compreensão dos fenômenos técnico-científicos que estão ocorrendo continuamente no meio social. Isso nos recorre a uma prática docente diversificada, quando o professor deve se equipar com o máximo de estratégias didáticas pertinentes ao processo de ensino para que facilite aos estudantes uma aprendizagem menos propedêutica e disciplinar, e desta forma tornar possível novas conexões entre os diversos ramos dos saberes científicos e suas implicações no contexto social.

Para além dos debates mencionados, observa-se que a proposta do ensino médio integrado no contexto amazônico-paraense conduz os professores para que atuem de modo a permitir ao estudante total autonomia para a escolha de decisões a serem tomadas frente a situações-problemas e temas para discorrer sobre suas ações, na posse de formular outras, e sempre alicerçados pela mediação docente para a produção do conhecimento com vistas à ACT, vislumbrando ideias, visões de mundo, opiniões e pensamentos sobre o estudo em questão, bem como na busca por referências bibliográficas seguras e confiáveis de informações quanto ao pretendido na discussão.

Finalmente, acreditamos que a nossa investigação não esgota a potencialidade da análise dos documentos oficiais da instituição frente ao perfil formativo do estudante para a prática social e no que concerne a uma integração do currículo no ensino médio, pois os elementos da alfabetização científica e técnica observados para os estudantes devem afirmar uma ação determinista para que coadunem de maneira mais geral com o que propõe Fourez (1994), e permitam-se identificar como protagonistas e com capacidade plena de discutir as descobertas da ciência e das tecnologias desenvolvidas para o meio social. Além disso, apropriar-se de conceitos científicos, integrando valores formativos, alinhando-se a conhecimentos além do proposto em sala de aula é crucial para fomentar um aprofundado da dimensão mais ampla da educação e sobre os conhecimentos científico-tecnológicos a partir do que a instituição oferece.

Para além dos elementos observados e discutidos, é importante frisar que para verificar a existência dessa vinculação de modo eficaz na formação dos jovens formados por esses cursos seria necessário investigar de modo minucioso o desenvolvimento de 
aulas, projetos e materiais didáticos que favorecem a aprendizagem dos alunos. Isso permitiria inferir se as convergências que observamos neste estudo documental se materializam em ações pedagógicas que visam a ACT.

\section{Referências}

Brasil (2012). Diretrizes Curriculares Nacionais para o Ensino Médio. Resolução n 2 , de 30 de janeiro de 2012. Define Diretrizes Curriculares Nacionais para o Ensino Médio. - Brasília: Câmara dos Deputados.

Brasil (1999). Parâmetros Curriculares Nacionais: Ensino Médio. Brasília: Ministério da Educação.

Brasil (1996). Lei de Diretrizes e Bases da Educação Nacional. Lei n 9.394, de 20 de dezembro de 1996. Estabelece as diretrizes e bases da educação nacional. Brasília: Câmara dos Deputados.

Brasil (2017). Lei $n^{\circ} 13.415$, de 16 de fevereiro de 2017. Conversão da Medida Provisória $n^{\circ} 746$, de 2016. Altera as Leis nos 9.394, de 20 de dezembro de 1996, que estabelece as diretrizes e bases da educação nacional, e 11.494, de 20 de junho 2007, que regulamenta o Fundo de Manutenção e Desenvolvimento da Educação Básica e de Valorização dos Profissionais da Educação, a Consolidação das Leis do Trabalho - CLT, aprovada pelo Decreto-Lei no 5.452, de 1 o de maio de 1943, e o Decreto-Lei no 236, de 28 de fevereiro de 1967; revoga a Lei no 11.161, de 5 de agosto de 2005; e institui a Política de Fomento à Implementação de Escolas de Ensino Médio em Tempo Integral. Brasília: Diário Oficial da União.

Brasil (2016). Medida Provisória $n^{\circ} 746$, de 22 de setembro de 2016. Dispõe sobre o reajuste dos benefícios mantidos pela previdência Social, e altera dispositivos das Leis $\mathrm{n}^{\circ}$ 6.015, de 31 de dezembro de 1973, 9.212 e 8.213, de 24 de julho de 1991, 9.604, de 5 de fevereiro de 1998, 9.639, de 25 de maio de 1998, 9.717, de 27 de novembro de 1998, e 9.796, de 5 de maio de 1999, e dá outras providências. Brasília: Diário Oficial da União.

Brito, L. P. (2001). Relatório de Pesquisa de Estágio Pós Doutoral PROCAD. Universidade Federal de Santa Catarina, Florianópolis.

Chassot, A. (2000). Alfabetização Científica: questões e desafios para a educação. ljuí: Editora da Unijuí.

Cunha, L. A. (2008). O ensino profissional na irradiação do industrialismo. São Paulo: Unesp.

Fourez, G. (1994). Alphabétisation Scientifique et Technique: essai sur les finalités de 
l'enseignement des sciences. Bruxelas: DeBoeck-Wesmael.

Frigotto, G., \& Ciavatta, M. \& Ramos, M. (Org.). (2005). Ensino médio integrado: concepção e contradições. São Paulo: Cortez.

Godoy, A. S. (1995). Introdução à pesquisa qualitativa e suas possibilidades. Revista de Administração de Empresas, 35(2), 57-73. DOI: http://dx.doi.org/10.1590/S003475901995000200008.

Lemke, J. L. (2006). Investigar para el Futuro de la Educación Científica: nuevas formas de aprender, nuevas formas de vivir, Enseñanza de las Ciencias, 24(1), 5-12.

Moraes, R., \& Galiazzi, M. C. (2011). Análise Textual Discursiva. Ijuí: Editora Unijuí.

Moura, D. H., Filho, D. L. L., \& Silva, M. R. (2015). Politecnia e formação integrada: confrontos conceituais, projetos políticos e contradições históricas da educação brasileira. Revista Brasileira de Educação, 20(60), 1057-1080. DOI: http://dx.doi. org/10.1590/S1413-24782015206313.

Rodrigues-Moura, S. (2016). Da World Wide Web às Partículas Elementares: sequência didática baseada no método DBR-TLS com vistas à alfabetização científica e técnica. (Dissertação de Mestrado em Docência em Educação em Ciências e Matemática), Universidade Federal do Pará, Belém.

Sebastião Rodrigues-Moura é Professor do Instituto Federal de Educação, Ciência e Tecnologia do Pará (IFPA), Campus Parauapebas, é licenciado em Ciências Naturais habilitação em Física. Mestre em Docência em Educação em Ciências e Matemática. Grupos de Pesquisa: Grupos de Estudos e Pesquisa em Rede para o Ensino de Física (GEPREF) e Grupo de Estudos e Pesquisa em Ciência, Tecnologia, Sociedade e Ambiente (GECTSA)

Licurgo Peixoto de Brito é Professor Titular da Universidade Federal do Pará (UFPA), lotado no Instituto de Ciências Exatas e Naturais e no Instituto de Educação Matemática e Científica onde atua em Programas de Pós-graduação em Educação em Ciências e Matemáticas e em Ensino de Física. Licenciado em Ciências - Física. Doutor em Geofísica. Pós-Doutor em Educação Científica e Tecnológica Grupo de Pesquisa: Grupo de Estudos e Pesquisa em Ciência, Tecnologia, Sociedade e Ambiente (GECTSA). 